\title{
Maternity waiting homes as part of a comprehensive approach to maternal and newborn care: a cross-sectional survey
}

Jody R. Lori ${ }^{*}$ (D), Joseph Perosky², Michelle L. Munro-Kramer², Phil Veliz², Gertrude Musonda ${ }^{3}$, Jameson Kaunda ${ }^{3}$, Carol J. Boyd ${ }^{4,5}$, Rachael Bonawitz ${ }^{6}$, Godfrey Biemba 7 , Thandiwe Ngoma ${ }^{8}$ and Nancy Scott ${ }^{6}$

\begin{abstract}
Background: Increased encounters with the healthcare system at multiple levels have the potential to improve maternal and newborn outcomes. The literature is replete with evidence on the impact of antenatal care and postnatal care to improve outcomes. Additionally, maternity waiting homes (MWHs) have been identified as a critical link in the continuum of care for maternal and newborn health yet there is scant data on the associations among MWH use and antenatal/postnatal attendance, family planning and immunization rates of newborns.
\end{abstract}

Methods: A cross-sectional household survey was conducted to collect data from women who delivered a child in the past 13 months from catchment areas associated with 40 healthcare facilities in seven rural Saving Mothers Giving Life districts in Zambia. Multi-stage random sampling procedures were employed with a final sample of $n=2381$. Logistic regression models with adjusted odds ratios and $95 \%$ confidence intervals were used to analyze the data.

Results: The use of a MWH was associated with increased odds of attending four or more antenatal care visits $(\mathrm{OR}=1.45,95 \% \mathrm{Cl}=1.26,1.68)$, attending all postnatal care check-ups $(\mathrm{OR}=2.00,95 \% \mathrm{Cl}=1.29,3.12)$ and taking measures to avoid pregnancy $(\mathrm{OR}=1.31,95 \% \mathrm{Cl}=1.10,1.55)$ when compared to participants who did not use a $\mathrm{MWH}$.

Conclusions: This is the first study to quantitatively examine the relationship between the use of MWHs and antenatal and postnatal uptake. Developing a comprehensive package of services for maternal and newborn care has the potential to improve acceptability, accessibility, and availability of healthcare services for maternal and newborn health. Maternity waiting homes have the potential to be used as part of a multi-pronged approach to improve maternal and newborn outcomes.

Trial registration: National Institutes of Health Trial Registration NCT02620436, Impact Evaluation of Maternity Homes Access in Zambia, Date of Registration - December 3, 2015.

Keywords: Antenatal care, Maternity waiting homes, Postnatal care, Zambia

\footnotetext{
*Correspondence: jrlori@umich.edu

'Office of Global Affairs, PAHO/WHO Collaborating Center, School of Nursing,

400 N. Ingalls, University of Michigan, Ann Arbor, MI 48109, USA

Full list of author information is available at the end of the article
}

(c) The Author(s). 2019 Open Access This article is distributed under the terms of the Creative Commons Attribution 4.0 International License (http://creativecommons.org/licenses/by/4.0/), which permits unrestricted use, distribution, and reproduction in any medium, provided you give appropriate credit to the original author(s) and the source, provide a link to the Creative Commons license, and indicate if changes were made. The Creative Commons Public Domain Dedication waiver (http://creativecommons.org/publicdomain/zero/1.0/) applies to the data made available in this article, unless otherwise stated. 


\section{Background}

It is well recognized that underutilization of life-saving health services has been associated with poor maternal and newborn outcomes [1]: however, multiple factors influence the use of maternal health services for women living in poor, remote communities. Zambia is a country with underutilization of health services; according to the Partnership for Maternal, Newborn and Child Health, Zambia is one of 49 global strategy priority countries [2]. The maternal mortality ratio in Zambia is 224 per 100,000 live births and infant mortality is reported at 45 deaths per 1000 live births [3]. The number of births projected for 2015 was 656,428 [4].

It has been established that antenatal care (ANC) can save lives by implementing timely and appropriate evidence-based practices [5]. Recently in Zambia, coverage of ANC significantly increased through efforts of the Millennium Development Goals (MDGs), with $96 \%$ of mothers attending at least one ANC visit with a skilled provider in 2015 [6]. However, according to the most recent Demographic and Health Survey only $55.5 \%$ of women attended four or more ANC visits [7], the number of visits deemed the most beneficial by the World Health Organization (WHO) until recently [5].

In addition to the importance of ANC care, the critical importance of the postnatal period is well established, with prior evidence suggesting that $60 \%$ of global maternal deaths occur during the postnatal period [8]. WHO recommends four postnatal checkups within the first six weeks on the following schedule: day $1(24 \mathrm{~h})$, day 3 (48-72 h), between days 7-14 and at six weeks postpartum [9]. An integral part of this postnatal care (PNC) is the provision of contraceptive education to postpartum women and routine vaccinations for their newborns [10]. In Zambia, $63 \%$ of women receive PNC in the critical first two days after delivery. Of these, the majority (48\%) are seen in the first four hours following delivery, $14 \%$ receive care within $4-23 \mathrm{~h}$, and $2 \%$ are seen $1-2$ days following delivery [7].

Maternity waiting homes (MWHs), also known as mother's shelters, are structures built near healthcare facilities to minimize the critical barrier of distance to accessing maternal health services. They serve as one potential health intervention that may be incorporated into a package of maternal and newborn health services. The Zambian government has identified MWHs as an intervention to increase demand for maternity care services, improve geographic access to facility delivery, and address the second delay: delay in reaching a health facility, first identified by Thaddeus and Maine in the three-delay model [11].

While WHO recognizes the value of MWHs as a critical link in the continuum of care, bringing women closer to healthcare facilities near the time of delivery
[12], MWHs can contribute to a larger health system strengthening effort to connect women to the health facility and to ANC and PNC services for both mothers and newborns. However, to date there is a dearth of literature documenting the relationship between the use of MWHs and ANC and PNC utilization. In theory, MWHs may be an important link within the continuum of care; however, there is scant data on whether women engage in all three services. Therefore, the objective of this study was to assess the associations among $\mathrm{MWH}$ use and ANC and PNC attendance, family planning, and immunization rates of newborns for mothers living in seven rural districts in Zambia.

\section{Methods}

A cross-sectional household survey design was used to collect data from women who delivered a child in the past 13 months from catchment areas associated with 40 healthcare facilities in seven rural districts that are part of the Saving Mothers, Giving Life (SMGL) initiative in Zambia: Choma, Kalomo, Lundazi, Mansa, Nyimba, Pemba, and Chembe in three provinces (Eastern, Luapula, and Southern) [13]. The SMGL initiative, launched in 2012, takes a health systems approach to improve access to safe, clean childbirth and timely emergency care. SMGL district study sites were selected for the study through formative reseach conducted in 2013-2014 $[14,15]$. The research methodology is described in detail elsewhere $[16,17]$. Ethical approval was obtained from Boston University Institutional Review Board (IRB), University of Michigan IRB, and the ERES Converge IRB in Zambia.

\section{Study sample and setting}

Multi-stage random sampling procedures were employed with probability proportionate to population size. First, the sampling frame of villages within the health facility catchment area located more than $9.5 \mathrm{~km}$ from the health facility, was derived through geo-coding; approximately 10 village clusters were randomly selected from each catchment area. In the second stage of sampling, all potentially eligible households within the selected villages were listed, randomly ordered, and then approached to contact an eligible participant. If more than one eligible participant was in the household, a single participant was randomly sampled. Inclusion criteria consisted of: 1) delivered within the past 13 months regardless of maternal or neonatal outcome OR a proxy participant if the woman was deceased (regardless of maternal or newborn outcome); 2) 15 years of age or older; if age 15-17, a legal guardian available to consent (proxy participants 18 years or older; 3 ) resident of a village 9.5 $\mathrm{km}$ or farther from the catchment area health facility. All eligible participants provided written informed 
consent prior to any survey procedures. Each survey took approximately $45 \mathrm{~min}$. Participants received a small token of appreciation, equivalent to \$2 USD in acknowledgment of their time.

\section{Data collection}

A team of local research assistants, literate in the appropriate local languages and English, were trained in human subjects' protection and data collection methods during a 5-day training. Data were captured electronically using SurveyCTO Collect Software installed on encrypted tablets in early 2016.

\section{Measures}

\section{Dependent variables - antenatal and postnatal care}

Several measures were used to assess the participants' use of ANC or PNC during their most recent pregnancy (within the past 13 months). Below are the items used to construct the dependent variables used in this analysis.

\section{Frequency of antenatal care}

A question asked participants the number of times they attended ANC at a health facility or health post. The response options included "none", "one time", "two times", "three times", "four times", and "more than four times". To capture the frequency of ANC visits for women, we dichotomized responses into those who attended ANC four or more times versus those who attended ANC three times or less.

\section{Postnatal care visits}

Participants could respond 'yes' or 'no' to questions regarding whether they went to a health facility or health post for "ANY postnatal checks after the first 24 hours following your last delivery"; "a postnatal check approximately 3 days after your last delivery"; "a postnatal check between 7 and 14 days after your last delivery"; and "a postnatal check approximately 6 weeks after you last delivery", aligned with WHO guidelines [9]. Two variables were created: one to assess any postnatal checks (yes versus no) and one to indicate attending all postnatal checks (visits $24 \mathrm{~h}$ after delivery, 3 days, 7 to 14 days, and 6 weeks after their last delivery).

\section{Contraception/avoiding pregnancy}

Participants were asked if they "currently use something or try in any way to delay or avoid getting pregnant?" The response options included "yes" and "no". This measure was treated as a dichotomous variable in the analyses.

\section{Vaccinations for child}

An additional question asked participants if their "... child received any vaccinations?” Response options were binary and included "yes" and "no" to assess if participants indicated that their child received specific vaccinations at birth (i.e., BCG and OPV-0), 6 weeks (i.e., OPV1, DTP-HepB-Hib-1, PCV, and Rotavirus), 10 weeks (i.e., OPV-2, DTP-HepB-Hib-2, PCV, and Rotavirus), and 14 weeks (i.e., OPV-3, DTP-HepB-Hib-3, and PCV), a binary variable (yes and no) was constructed to distinguish whether participants indicated receiving all of the required vaccinations for their child depending on age versus those who did not complete the full cycle of vaccinations for their child. Responses were checked against vaccination cards in $79 \%$ of cases $(n=1677)$ and controlled for infant status at time of survey. Mothers whose babies died $(n=48)$ were excluded from the immunization analysis.

\section{Independent variables - maternity waiting home use}

The primary independent variable was whether the mother used a MWH for her most recent delivery. Participants were asked if they stayed "at a mothers' shelter for any reason at all before or after that delivery." Participants had two response options: "yes" and "no". The variable was treated as a dichotomous variable in the analyses outlined below.

\section{Control variables}

Control variables included household size, marital status, number of births, sex of the head of household, age, and educational level for the mothers who participated in the study.

\section{Data analysis}

STATA 15.0 was used to estimate the models outlined above (Version 15.0; StataCorp LP, College Station, Texas). All logistic regression models included adjusted odds ratios (AOR) and 95\% confidence intervals (95\% CI). Additionally, models accounted for clustering within each of the seven districts where the sample of participants were obtained.

\section{Results}

The response rate was $86.9 \%$ with a final sample of 2381 participants from unique households. Of those eligible but who did not respond: $280(10.2 \%)$ were unavailable primarily due to their work in the fields for the harvest, $60(2.2 \%)$ refused participation, and $20(0.7 \%)$ withdrew after beginning the survey or had incomplete surveys and were dropped from the analysis.

Overall, $58.6 \%$ of our sample attended four or more ANC visits; $3.6 \%$ of participants attended ANC between 0 and 1 time, while $37.8 \%$ attended ANC between 2 and 3 times. Over $45 \%$ reported at least one PNC visit (14.2\% attended 1 to 2 PNC visits, $25.7 \%$ attended three PNC visits, and $6.4 \%$ went to all PNC visits) with respect 
to their most recent pregnancy and birth (Table 1). Approximately $34.5 \%$ of participants indicated using some form of contraception after their most recent birth. The majority (91.1\%) reported immunizing their newborn; however, among the sample of participants whose child was 14 weeks of age or older, only $39.1 \%$ indicated their child had received all of the required vaccinations. Participants reported $65.2 \%$ of newborns received all recommended vaccinations at birth (BCG and Oral Polio [OPV-0]); 83.6\% received the full recommended list at 6-weeks (OPV-1, DPT-HepB-Hib-1); 73.8\% at 10weeks (OPV-2, DPT-HepB-Hib2); and $57.4 \%$ at 14 weeks (OPV-3, DPT-HepB-Hib3).

Assessing the bivariate associations between sociodemographic characteristics and ANC and PNC reveals several statistically significant associations. Larger household size was negatively associated with attending four or more ANC visits, attending any PNC visit, and using some form of contraception to avoid pregnancy (Table 1). Participants living in households with seven or more people had lower odds of attending any PNC visit $(\mathrm{OR}=.730$, $95 \% \mathrm{CI}=.585, .911)$ and of attempting to prevent pregnancy $(\mathrm{OR}=.630,95 \% \mathrm{CI}=.445, .891)$ when compared to women living in smaller households of 1-3 people. Marital status was only associated with attempting to prevent pregnancy; mothers who were not married had lower odds of attempting to prevent pregnancy when compared to mothers who were married (OR $=.293,95 \%$ $\mathrm{CI}=.208, .411$ ).

Number of previous births was associated with several of the listed outcomes in Table 1. Participants with two or more children were less likely to attend any PNC visit (2-3 children, $\mathrm{OR}=.783,95 \% \mathrm{CI}=.633, .969 ; 4$ or more children, $\mathrm{OR}=.783,95 \% \mathrm{CI}=.656, .934$ ) but significantly more likely to use contraception (2-3 children, OR = $.1 .54,95 \% \mathrm{CI}=1.35,1.76 ; 4$ or more children, $\mathrm{OR}=$ $1.18,95 \% \mathrm{CI}=1.01,1.38)$, and to have their child immunized $(2-3$ children, $\mathrm{OR}=1.40,95 \% \mathrm{CI}=1.15,1.70,4$ or more children, $\mathrm{OR}=1.25,95 \% \mathrm{CI}=1.04,1.50$ ) than women with only one child.

Participants who lived in households headed by females had higher odds of attending any PNC visit (OR = $1.73,95 \% \mathrm{CI}=1.45,2.08)$ and attending all four PNC check-ups $(\mathrm{OR}=2.83,95 \% \mathrm{CI}=1.51,5.29)$, while those who lived in households where a head of household could not be identified (response reported as 'unknown') had lower odds of taking measures to avoid pregnancy when compared to mothers who lived in households headed by males $(\mathrm{OR}=.388,95 \% \mathrm{CI}=.283, .532)$.

Maternal age had a significant influence on attempting to avoid pregnancy with participants aged 20-30 years all having higher odds of avoiding pregnancy when compared to those aged 15-19 (20-24 years, OR $=1.71,95 \%$ $\mathrm{CI}=1.39,2.10 ; 25-29$ years $, \mathrm{OR}=1.37,95 \% \mathrm{CI}=1.20$,
1.56; $30-34$ years, $\mathrm{OR}=1.40,95 \% \mathrm{CI}=1.18,1.66$ ). Age also had a significant influence on childhood immunizations with participants 25-29 years and 30-34 years reporting higher levels of any childhood immunizations $(\mathrm{OR}=1.26,95 \% \mathrm{CI}=1.06,1.50$ and $\mathrm{OR}=1.69,95 \% \mathrm{CI}=$ 1.03, 2.77 respectively).

Finally, participants' level of education was positively associated with avoiding pregnancy and reporting any immunizations for their child. In particular, participants who had some primary education had higher odds of avoiding pregnancy $(\mathrm{OR}=1.31,95 \% \mathrm{CI}=1.17,1.47)$ and obtaining any childhood immunizations for their most recent birth $(\mathrm{OR}=1.47,95 \% \mathrm{CI}=1.08,1.99)$ when compared to those with no education.

The associations between using a MWH during the most recent pregnancy and utilization of both ANC and PNC are included in Table 2 . Among participants in the sample, $31.5 \%$ indicated using a MWH for their most recent pregnancy. The results indicate the use of a MWH was associated with increased odds of attending four or more ANC visits $(\mathrm{OR}=1.45,95 \% \mathrm{CI}=1.26,1.68)$, attending all PNC check-ups $(\mathrm{OR}=2.00,95 \% \mathrm{CI}=1.29$, $3.12)$, and taking measures to avoid pregnancy $(\mathrm{OR}=$ $1.31,95 \% \mathrm{CI}=1.10,1.55)$ when compared to participants who did not use a MWH.

After controlling for household size, marital status, number of births, sex of the head of household, maternal age, and educational level, the observed associations between $\mathrm{MWH}$ use and the increased odds of attending four or more $\mathrm{ANC}$ visits $(\mathrm{AOR}=1.43,95 \% \mathrm{CI}=1.25$, 1.65), attending all PNC check-ups (AOR $=1.99,95 \%$ $\mathrm{CI}=1.30,3.07$ ), and taking measures to avoid pregnancy $(\mathrm{AOR}=1.27,95 \% \mathrm{CI}=1.08,1.50)$ remained significant. Moreover, several sociodemographic variables still predict several of the ANC and PNC outcomes. Young mothers, between the ages of 15 and 19, had lower odds of optimum utilization of ANC and PNC when compared to participants who were in older age groups. Larger household size, unmarried status, and residing in households headed by males also show significantly lower odds related to the postnatal outcomes (Table 3).

\section{Discussion}

Thirty-one percent of our sample reported using a MWH during their last pregnancy. Results indicate a positive association between $\mathrm{MWH}$ use and number of ANC visits (four or more visits), attending all PNC visits, and increased contraceptive use of any kind to avoid pregnancy. Although directionality cannot be established, our results highlight the potential influence of a comprehensive package of services for women living in rural, remote areas.

Studies have shown a positive influence between attendance at ANC and PNC services and use of a skilled 


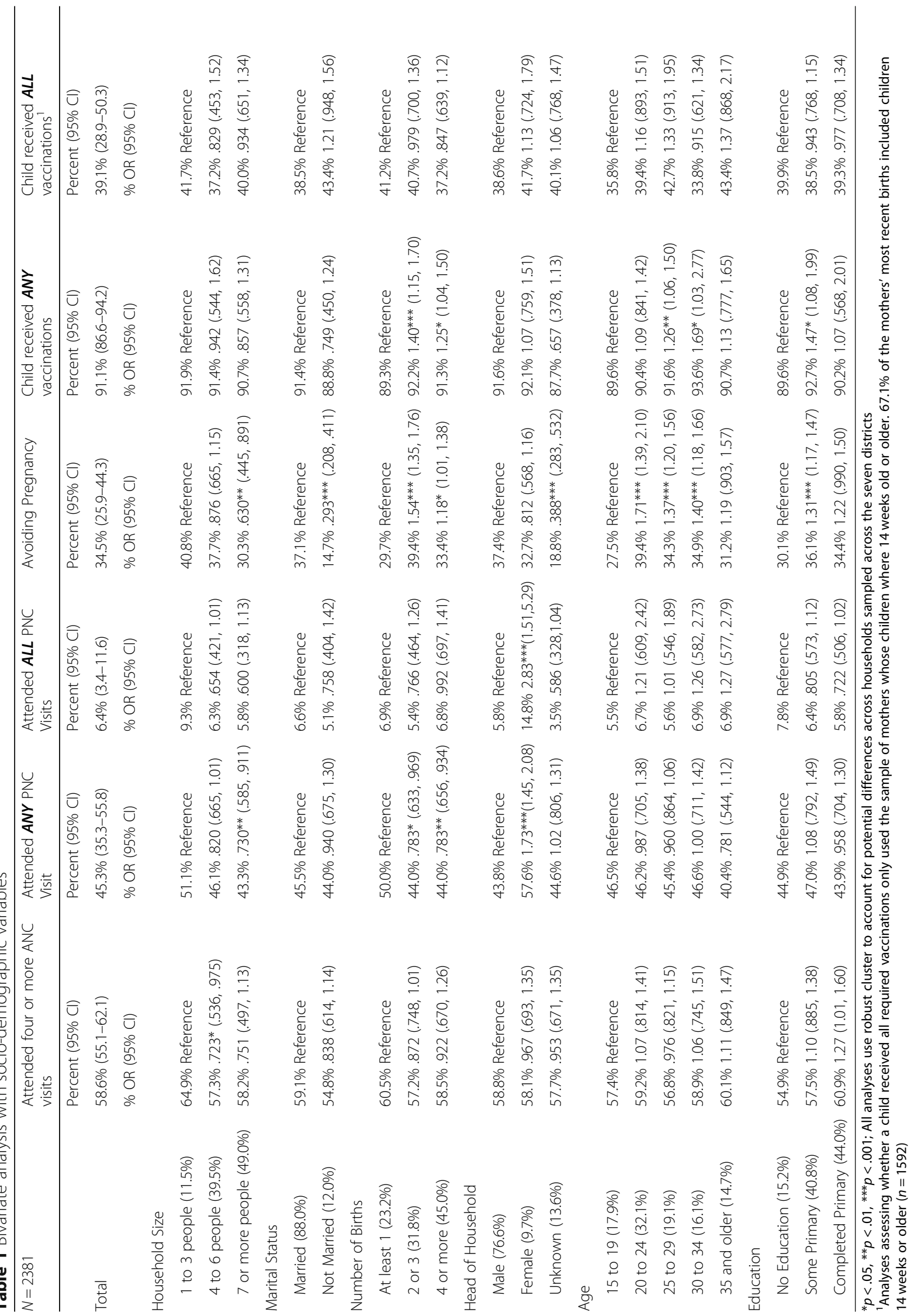




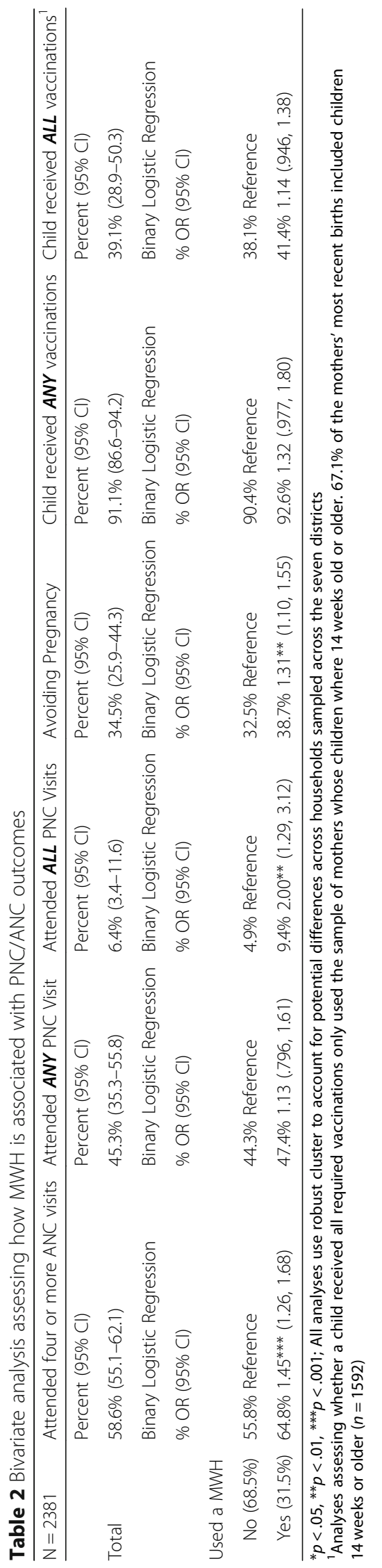




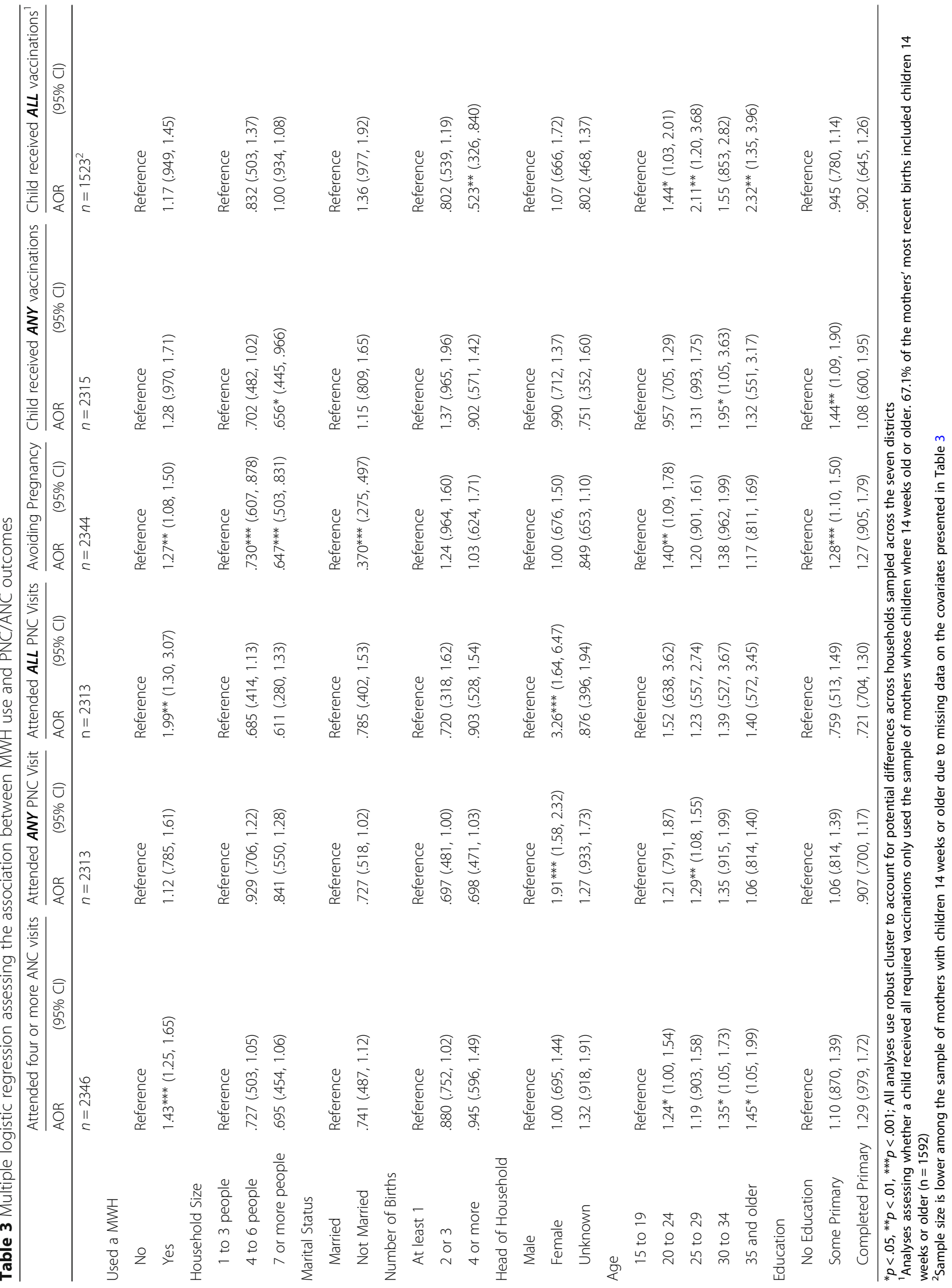


birth attendant for delivery as well as uptake of modern family planning methods $[18,19]$. Additionally, the use of MWHs has been associated with an increase in facility delivery and skilled birth attendance [20, 21]. Maternity waiting homes as an intervention to increase facility-based delivery may provide a conduit for enhanced communication and community outreach, both of which have the potential to influence ANC, PNC, and family planning uptake [22].

Less than half $(45.3 \%)$ of participants in our study attended any PNC, far less than the $63 \%$ of women reported in the Zambia Demographic and Health Survey [7]. This could be due to rugged terrain and long distances to healthcare facilities for participants living in the seven districts in our study. Just as geographic distance may decrease facility utilization for birth, that same distance may represent a challenge to attending the recommended number of PNC visits. Household size also had a significant effect on whether women attended PNC and their attempts to avoid pregnancy, with participants living in larger households less likely to attend $\mathrm{PNC}$ and to be using any form of contraception. One notable finding was that participants living in femaleheaded households were more likely than those from homes with a male head of household to attend postnatal care. This may be a reflection of women's household position and their autonomy in decision-making [23].

Postnatal care is an effective intervention for childhood immunizations and the uptake of family planning services $[18,24]$. In this study, the use of a MWH was associated with an increased uptake of PNC care and subsequently increased avoidance of pregnancy. Previous studies have reported an association between PNC care and modern contraceptive use in Kenya, Zambia, and Ethiopia [18, 24]. The findings of this study suggest the expansion of a comprehensive maternal, newborn, and child health package of service to include MWHs has the potential to further increase PNC care and use of contraceptive services.

Although there was an association between use of a MWH and attendance at all PNC visits, there was no relationship between MWH use and childhood immunizations. The immunization schedule in Zambia follows the WHO recommendations for childhood immunization [25]. Interestingly, 91\% of subjects reported their infant received at least one childhood immunization. The lack of an increase in receiving at least one immunization with the use of a MWH may be due to a ceiling effect as well as the fact that the first immunizations including BCG and Hepatitis B are given immediately at birth while the mother and newborn are still at the health facility.

Developing a comprehensive package of services for maternal and newborn care has the potential to improve the availability, accessibility and acceptability of care for mothers and newborns in low-resource settings [26]. Increased encounters with the healthcare system at multiple levels have the potential to improve maternal and newborn outcomes.

\section{Limitations}

This study has four main limitations. First, this is a crosssectional study and we cannot assess directionality or change over time; however, it is unique in that it is a large sample size and contains numerous variables on a representative sample of a remote population. Second, this study is limited by its focus on the Saving Mothers Giving Life (SMGL) districts which constrains generalization beyond the SMGL districts selected for this study. The seven districts in our study are part of the 10 learning districts included in the SMGL five-year public private partnership to decrease maternal mortality by $50 \%$ and perinatal mortality by $30 \%$ in Uganda and Zambia with a plan to then scale up nationally in both countries [13]. These districts have had considerable resources provided over the course of the past five years and it is likely that outcomes in these districts are better than others. Additionally, several questions relied on participant's recall of events over the past 13 months potentially affecting the accuracy or completeness of the recollections retrieved by participants as well as the possibility of social desirability bias. Finally, at the end of this study, there were no national policies regarding standardization of MWHs in Zambia, therefore wide variation could exist at each MWH.

\section{Conclusions}

This is the first study to quantitatively examine the relationship between the use of MWHs and ANC and PNC utilization. Providing a comprehensive approach to maternal and newborn health with the appropriate utilization of services can have a positive impact on maternal and newborn outcomes [19]. Our findings suggest MWHs are associated with some healthy behaviors among women who use them (e.g., attendance at four or more ANC visits, attendance at all PNC visits, and taking measures to avoid pregnancy). Maternity waiting homes can be used as part of a multi-pronged approach to improving maternal and newborn services, ultimately increasing access to and attendance at ANC and PNC. By taking a holistic approach to maternal and newborn services, MWHs have the potential to increase contacts with the healthcare system and improve maternal and newborn outcomes. Future research is needed on the cost implications of such a strategy and the long term sustainability of MWHs for resource poor settings such as Zambia. 


\section{Abbreviations}

ANC: Antenatal care; AOR: Adjusted odds ratio; BCG: Bacille Calmette-Guérin; Cl: Confidence interval; DPT: Diphtheria, Pertussis, Tetanus; HepB: Hepatitis B; Hib: Haemophilus-influenzae-type-b; IRB: Institutional Review Board; MDG: Millennium Development Goals; MWH: Maternity waiting home; OPV: Oral polio vaccine; OR: Odds ratio; PNC: Postnatal care; SMGL: Saving Mothers, Giving Life; USD: United States dollar; WHO: World Health Organization

\section{Acknowledgements}

None applicable.

\section{Authors' contributions}

JL, MM-K, CB, GM, NS, TN, and GB conceived the study and established the study protocol. GB, GM, and TN assisted with data collection. PV, JP, JL, $M M-K$, and CB conducted the data analysis. JL, MM-K, JP, MM-K, PV, GM, JK, $\mathrm{CB}, \mathrm{RB}, \mathrm{GB}, \mathrm{TN}$, and NS all contributed to developing the content for the manscript, writing and editing sections, and reviewed the final draft. All authors read and reviewed the final manuscript. None of the authors report any conflicts of interest.

\section{Funding}

This program was developed and is being implemented in collaboration with MSD for Mothers, MSD's 10-year, \$500 million initiative to help create a world where no woman dies giving life. MSD for Mothers is an initiative of Merck \& Co., Inc., Kenilworth, N.J., U.S.A. (MRK 1846-06500.COL). The development of this article was additionally supported in part by the Bill \& Melinda Gates Foundation (OPP1130334) https://www.gatesfoundation.org/ How-We-Work/Quick-Links/Grants-Database/Grants/2015/06/OPP1130334 Database/Grants/2015/07/OPP1130334 and The ELMA Foundation (ELMA-15F0017) http://www.elmaphilanthropies.org/the-elma-foundation/ The funders had no role in study design, data collection and analysis, decision to publish, or preparation of the manuscript. The content is solely the responsibility of the authors and does not necessarily reflect positions or policies of MSD, the Bill \& Melinda Gates Foundation, or The ELMA Foundation.

\section{Availability of data and materials}

Data used for this manuscript are part of an on-going clinical trial. The Boston University IRB and the ERES Converge IRB in Zambia approved that data would only be presented in aggregate form. Additionally, the consent forms explicitly state the data will be only shared in aggregate form. Once the clinical trial is complete and primary results have been disseminated the data will be released. Data requests may be sent to the Boston University IRB at: medirb@bu.edu.

We would also like to confirm we will be able to share the minimal anonymized data set if and when our manuscript is accepted for publication.

\section{Ethics approval and consent to participate}

Institutional Review Board approval was obtained from Boston University Institutional Review Board (IRB), University of Michigan IRB, and the ERES Converge (Where Research, Ethics, and Science Converge) IRB, a private research ethics committee in Zambia governed by the National Health Research Ethics Committee. All informed consent was documented with a signature or mark. When a participant was unable to write, a mark (thumbprint) was made and the written informed consent was signed by a witness. For participants between the ages of 15-17 years of age, ascent was first obtained and then their guardian or husband provided written consent. This allowed the woman to first determine if she wished to join the study (ascent), therefore protecting her individual wishes. If a woman's husband was 18 or older, he provided informed consent on behalf of his wife. All participants retained a copy of the informed consent form. The consent process was approved by all IRBs.

\section{Consent for publication}

Not applicable - no individual participant data are included.

\section{Competing interests}

The authors declare they have no competing interest.

\section{Author details}

Office of Global Affairs, PAHO/WHO Collaborating Center, School of Nursing, 400 N. Ingalls, University of Michigan, Ann Arbor, Ml 48109, USA. ${ }^{2}$ School of Nursing, University of Michigan, 400 N. Ingalls, Ann Arbor, MI 48109, USA. ${ }^{3}$ Africare-Zambia, Flat A, Plot 2407/10 MBX, Off Twin Palm Road, Ibex Hill, Box, 33921 Lusaka, Zambia. ${ }^{4}$ Center for the Study of Drugs, Alcohol, Smoking and Health, School of Nursing, University of Michigan, Ann Arbor, MI 48109, USA. ${ }^{5}$ Institute for Research on Women and Gender, University of Michigan, Ann Arbor, Ml 48109, USA. ${ }^{6}$ School of Public Health, Boston University, Boston, MA 02118, USA. ${ }^{7}$ Boston University, School of Public Health, Director/ CEO, National Health Research Authority (NHRA), Lusaka, Zambia. ${ }^{8}$ Right to Care Zambia, Lusaka, Zambia.

Received: 15 July 2018 Accepted: 27 June 2019

Published online: 04 July 2019

\section{References}

1. Stanton ME, Higgs ES, Koblinsky M. Investigating financial incentives for maternal health: an introduction. J Health Popul Nutr. 2013;31(4 Suppl 2):S1.

2. WHO. Partnership for Maternal, Newborn \& Child Health, Burden of Disease, Progress on MDG4 and 5A in Countdown to 2015 Countries, and Number of Commitments [Internet]. Geneva; 2012 [cited 2018 Jan 6]. Available from: http://www.who.int/pmnch/topics/part_publications/2012_pmnch_report_ ann3.pdf.

3. WHO. Zambia - Country Profile [Internet]. Geneva; 2015 [cited 2018 Jan 6]. Available from: http://www.who.int/countries/zmb/en/.

4. Central Statistics Office (CSO). Population and demographic projections 2011-2035 [internet]. Zambia data portal; 05 July 2013 [cited 2018 Jan 6]. Available from: http://zambia.opendataforafrica.org/ZMPHC2015/populationand-demographic-projections-2011-2035.

5. WHO. WHO recommendations on antenatal care for a positive pregnancy experience [internet]. Geneva; 2016 [cited 2017 Dec 13]. Available from: http://apps.who.int/iris/bitstream/10665/250796/1/9789241549912-eng. pdf?ua=1

6. Kearns A, Caglia J, Hoope-Bender P, Langer A. Antenatal and postnatal care: a review of innovative models for improving availability, accessibility, acceptability and quality of services in low-resource settings. BJOG: An International Journal of Obstetrics \& Gynaecology. 2016;123(4):540-8.

7. CSO. Zambia Demographic and Health Survey 2013-14 [Internet]. Rockville (MA, USA): Ministry of Health (MOH) (Zambia), and ICF International; 2014 [cited 2018 Jan 6]. Available from: https://www.dhsprogram.com/pubs/pdf/ fr304/fr304.pdf

8. Li X, Fortney J, Kotelchuck M, Glover L. The postpartum period: the key to maternal mortality. Int J Gynecol Obstet. 1996;54(1):1-10.

9. $\mathrm{WHO}$. WHO recommendations on postnatal Care of the Mother and Newborn [internet]. Geneva; 2013 Oct [cited 2018 Mar 20]. Available from: http://apps.who.int/iris/bitstream/10665/97603/1/9789241506649_eng. pdf?ua=1.

10. Salam RA, Mansoor T, Mallick D, Lassi ZS, Das JK, Bhutta ZA. Essential childbirth and postnatal interventions for improved maternal and neonatal health. Reprod Health. 2014;11(1):S3.

11. Thaddeus S, Maine D. Too far to walk: maternal mortality in context. Soc Sci Med. 1994:38(8):1091-110.

12. World Health Organization. Maternity waiting homes: a review of experiences. 1996.

13. Saving Mothers, Giving Life. Saving Mothers Giving Life [Internet]. Zambia; 2017 [cited 2018 Jan 6]. Available from: http://savingmothersgivinglife.org/ our-work/zambia.aspx

14. Lori JR, Munro-Kramer ML, Mdluli EA, Musonda GK, Boyd CJ. Developing a community driven sustainable model of maternity waiting homes for rural Zambia. Midwifery. 2016:41:89-95.

15. Scott NA, Vian T, Kaiser JL, Ngoma T, Mataka K, Henry EG, Biemba G, Nambao M, Hamer DH. Listening to the community: using formative research to strengthen maternity waiting homes in Zambia. PLoS One. 2018;13:e0194535.

16. Scott NA, Kaiser JL, Vian T, Bonawitz R, Fong RM, Ngoma T, Biemba G, Boyd CJ, Lori JR, Davidson HH, Rockers PC. Impact of maternity waiting homes on facility delivery among remote households in Zambia: protocol for a quasiexperimental, mixed-methods study. BMJ Open. 2018;8:e022224.

17. Lori JR, Boyd CJ, Munro-Kramer ML, Veliz PT, Henry EG, Kaiser J, Munsonda $\mathrm{G}$, Scott N. Characteristics of maternity waiting homes and the women who 
use them: Findings from a baseline cross-sectional household survey among SMGL-supported districts in Zambia, Plos One 2018; [cited 2019 Jun 20]. Available from: https://doi.org/10.1371/journal.pone.0209815.

18. Do M, Hotchkiss D. Relationships between antenatal and postnatal care and post-partum modern contraceptive use: evidence from population surveys in Kenya and Zambia. BMC Health Serv Res. 2013;13(1):6.

19. Jacobs C, Moshabela M, Maswenyeho S, Lambo N, Michelo C. Predictors of antenatal care, skilled birth attendance, and postnatal care utilization among the remote and poorest rural communities of Zambia: a multilevel analysis. Front Public Health. 2017;5:11.

20. Henry EG, Semrau K, Hamer DH, Vian T, Nambao M, Mataka K, et al. The influence of quality maternity waiting homes on utilization of facilities for delivery in rural Zambia. Reprod Health. 2017;14(1):68.

21. Lori JR, Munro ML, Rominski S, Williams G, Dahn BT, Boyd CJ, et al. Maternity waiting homes and traditional midwives in rural Liberia. Int J Gynecol Obstet. 2013;123(2):114-8.

22. Jacobs C, Michelo C, Chola M, Oliphant N, Halwiindi H, Maswenyeho S, et al. Evaluation of a community-based intervention to improve maternal and neonatal health service coverage in the most rural and remote districts of Zambia. PLoS One. 2018;13(1):e0190145.

23. Acharya DR, Bell JS, Simkhada P, Van Teijlingen ER, Regmi PR. Women's autonomy in household decision-making: a demographic study in Nepal. Reprod Health. 2010;7(1):15

24. Regassa N. Antenatal and postnatal care service utilization in southern Ethiopia: a population-based study. African health sciences. 2011;11(3)

25. WHO. Immunizations and vaccines development. [internet]. Geneva; 2018 [cited 2018 Feb 21]. Available from: http://www.aho.afro.who.int/profiles information/index.php/Zambia:Immunization_and_vaccines_ development\#Immunization_schedule.

26. Lori JR, Wadsworth AC, Munro ML, Rominski S. Promoting access: the use of maternity waiting homes to achieve safe motherhood. Midwifery. 2013;29(10):1095-102.

\section{Publisher's Note}

Springer Nature remains neutral with regard to jurisdictional claims in published maps and institutional affiliations.

Ready to submit your research? Choose BMC and benefit from:

- fast, convenient online submission

- thorough peer review by experienced researchers in your field

- rapid publication on acceptance

- support for research data, including large and complex data types

- gold Open Access which fosters wider collaboration and increased citations

- maximum visibility for your research: over $100 \mathrm{M}$ website views per year

At $\mathrm{BMC}$, research is always in progress.

Learn more biomedcentral.com/submissions 